Prepared in cooperation with the U.S. Fish and Wildlife Service

Synthetic Aperture Radar and Optical Mapping Used to Monitor Change and Replacement of Phragmites australis Marsh in the Lower Mississippi River Delta, Louisiana

Open-File Report 2021-1046 
Cover. Photograph showing Phragmites australis marsh replacement by elephant-ear in 2019, lower Mississippi River Delta, Louisiana. 


\section{Synthetic Aperture Radar and Optical Mapping Used to Monitor Change and Replacement of Phragmites australis Marsh in the Lower Mississippi River Delta, Louisiana}

By Elijah W. Ramsey III and Amina Rangoonwala

Prepared in cooperation with the U.S. Fish and Wildlife Service

Open-File Report 2021-1046 


\section{U.S. Geological Survey, Reston, Virginia: 2021}

For more information on the USGS - the Federal source for science about the Earth, its natural and living resources, natural hazards, and the environment—visit https://www.usgs.gov or call 1-888-ASK-USGS.

For an overview of USGS information products, including maps, imagery, and publications, visit https://store.usgs.gov/.

Any use of trade, firm, or product names is for descriptive purposes only and does not imply endorsement by the U.S. Government.

Although this information product, for the most part, is in the public domain, it also may contain copyrighted materials as noted in the text. Permission to reproduce copyrighted items must be secured from the copyright owner.

Suggested citation:

Ramsey, E.W., III, and Rangoonwala, A., 2021, Synthetic aperture radar and optical mapping used to monitor change and replacement of Phragmites australis marsh in the lower Mississippi River Delta, Louisiana: U.S. Geological Survey Open-File Report 2021-1046, 19 p., https://doi.org/10.3133/ofr20211046.

ISSN 2331-1258 (online) 


\section{Acknowledgments}

We thank William G. Thomas II (Invasive Species Coordinator/Strike Team Leader, U.S. Fish and Wildlife Service [FWS] Region 4) for supporting our proposed work and Sue Wilder, previously with the FWS, for help in preparing the study proposal. Neil Lalonde (Project Leader at the FWS Southeast Louisiana National Wildlife Refuges [NWR] Complex) and Barret K. Fortier (Regional Energy Coordinator I, Southeast Region, and Acting Refuge Manager for the Delta and Breton NWRs) are thanked for allowing access to the Delta NWR and for providing transport to the field sites throughout the NWR. We thank Max Latham, FWS, whose knowledge and persistence helped us obtain the field data we needed for this study.

The Advanced Land Observing Satellite (ALOS) and ALOS-2 data used in this study were provided to the U.S. Geological Survey by the Japan Aerospace Exploration Agency (JAXA) and Japan Resources Observation System Organization (JAROS) under a Collaborative Research Agreement (nonfunded). 



\section{Contents}

Acknowledgments ……...................................................................................................................

Abstract

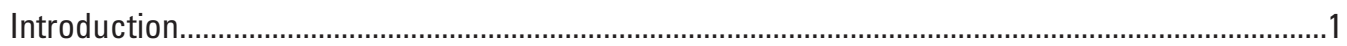

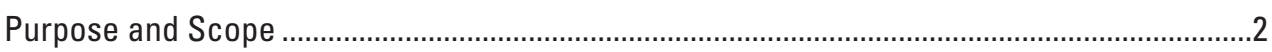

Study Area

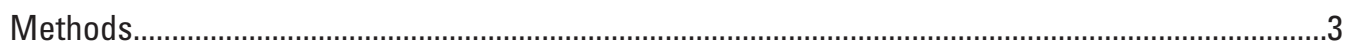

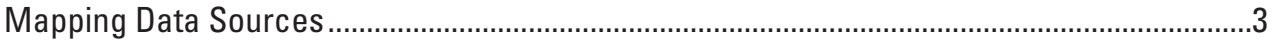

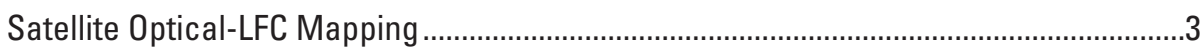

Satellite SAR and $P$. australis Marsh Density....................................................................

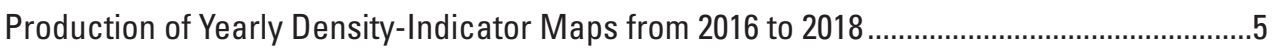

Water Mask Creation and Above-Surface Water Levels ............................................................

Site Selection and Field Data Collections................................................................................

Challenges in Relating Field to Satellite Measurements ....................................................

HV, LFC, and Elephant-Ear Graphical Comparisons .................................................................

Elephant-Ear Increase and HV and LFC Response ....................................................

Fused HV-Density and Optical-LFC Trajectory Status Monitors ......................................6

Field Site Trajectory Plots...............................................................................................

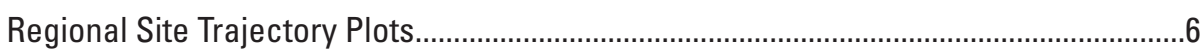

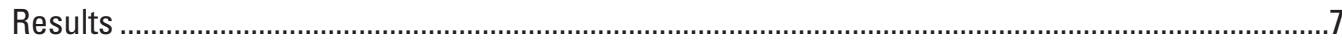

ALOS HV-Density-Indicator Mapping.............................................................................

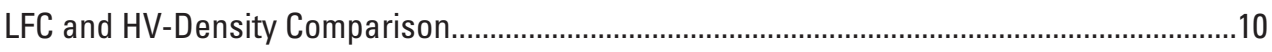

2018 and 2019 Field Site Comparison........................................................................ 10

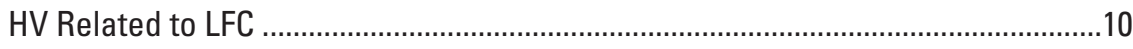

Elephant-Ear Increase Related to HV and LFC ...................................................10

Trajectory Descriptions and Comparisons ……………….....................................................10

Field Trajectory Descriptions and Comparisons ..............................................................10

Regional Trajectory Descriptions and Comparisons..........................................................10

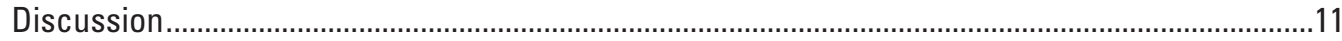

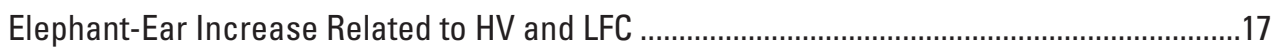

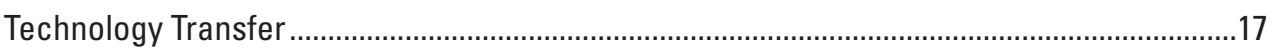

Summary

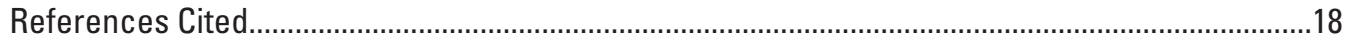

\section{Figures}

1. A Sentinel-2 optical image of the lower Mississippi River Delta study region,

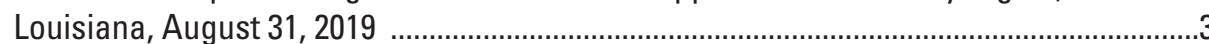

2. Image showing Phragmites australis within the U.S. Fish and Wildlife Service Delta National Wildlife Refuge in 2016 ..........................................................................

3. Webcam photographs of two field sites: site S1, 2018; site S1, 2019; site S3, 2018; and site S3, 2019

4. Composited Advanced Land Observing Satellite synthetic aperture radar HV images, 2016, 2017, 2018, and 2019 
5. Advanced Land Observing Satellite-2 HV color composite displaying the 2016 HV amplitude as red, $2017 \mathrm{HV}$ amplitude as green, and $2018 \mathrm{HV}$ amplitude as blue ........9

6. Graphs showing the 2019 minus 2018 elephant-ear difference compared to the 2019 minus 2018 HV-amplitude and live fractional cover differences at berm sites ......11

7. Graphs showing trajectories for Sentinel-2 live fractional cover and Advanced Land Observing Satellite-2 HV amplitudes for field sites, 2016-19

8. Sentinel-2 composite image showing live fractional cover for 2016, 2017, and 2018; and Advanced Land Observing Satellite-2 composite image showing HV amplitudes for 2016, 2017, and 2018

9. Sentinel-2 composite image showing live fractional cover for 2016, 2017, and 2018; and Advanced Land Observing Satellite-2 composite image showing HV amplitudes for 2016, 2017, and 2018

10. Graphs showing trajectories for Sentinel-2 live fractional cover and Advanced Land Observing Satellite-2 HV backscatter amplitudes for regional sites, 2016-19 ......15

\section{Tables}

1. Surface-water levels at Louisiana Coastwide Reference Monitoring System sites in the U.S. Fish and Wildlife Service Delta National Wildlife Refuge at the times of image collections

2. Simple regressions describing HV and LFC relationships

3. Mid-range normalized HV and LFC differences between years at field sites and regional sites at the U.S. Fish and Wildlife Service Delta National Wildlife Refuge, 2016-19.

\section{Conversion Factors}

International System of Units to U.S. customary units

\begin{tabular}{|c|c|c|}
\hline Multiply & By & To obtain \\
\hline \multicolumn{3}{|c|}{ Length } \\
\hline meter (m) & 3.281 & foot $(\mathrm{ft})$ \\
\hline kilometer (km) & 0.6214 & mile (mi) \\
\hline kilometer (km) & 0.5400 & mile, nautical (nmi) \\
\hline meter $(\mathrm{m})$ & 1.094 & yard (yd) \\
\hline
\end{tabular}

Temperature in degrees Fahrenheit $\left({ }^{\circ} \mathrm{F}\right)$ may be converted to degrees Celsius $\left({ }^{\circ} \mathrm{C}\right)$ as follows: ${ }^{\circ} \mathrm{C}=\left({ }^{\circ} \mathrm{F}-32\right) / 1.8$. 


\section{Abbreviations}

$\begin{array}{ll}< & \text { less than } \\ \leq & \text { less than or equal to } \\ \text { ALOS } & \text { Advanced Land Observing Satellite } \\ \text { CRMS } & \text { Coastwide Reference Monitoring System } \\ \text { EE } & \text { elephant-ear (Colocasia esculenta) } \\ \text { FWS } & \text { U.S. Fish and Wildlife Service } \\ \text { GSA } & \text { ground surface area } \\ \text { HH } & \text { horizontal send and horizontal return } \\ \text { HV } & \text { horizontal send and vertical return } \\ \text { LFC } & \text { live fractional cover } \\ \text { NDVI } & \text { normalized difference vegetation index } \\ \text { NWR } & \text { National Wildlife Refuge } \\ \text { PALSAR } & \text { phased array type L-band SAR radar } \\ \text { SAR } & \text { synthetic aperture radar } \\ \text { USGS } & \text { U.S. Geological Survey } \\ \text { VH } & \text { vertical send and horizontal return } \\ \text { VV } & \text { vertical send and vertical return }\end{array}$





\title{
Synthetic Aperture Radar and Optical Mapping Used to Monitor Change and Replacement of Phragmites australis Marsh in the Lower Mississippi River Delta, Louisiana
}

\author{
By Elijah W. Ramsey III ${ }^{1}$ and Amina Rangoonwala ${ }^{2}$
}

\section{Abstract}

Synthetic aperture radar (SAR) mapping of density as an enhancement of Phragmites australis optical live fractional cover (LFC) mapping was carried out in the lower Mississippi Delta during 2016 to 2019. Also, as part of the study, the replacement of $P$. australis with elephant-ear was analyzed. To that end, yearly maps from 2016 to 2019 of L-band SAR horizontal send, vertical receive (HV) data representing marsh density were produced for the lower Mississippi River Delta. The mapping indicated high local variability within broad yearly density change in $P$. australis marsh. LFC mapping indicated a similar pattern of broad yearly change. That overall density and LFC linear correspondence was confirmed with regressions of $P$. australis marsh $\mathrm{HV}$-density data and optical-LFC data. Local differences reflected as high scatter in the plots. Based on those results, a combined LFC and HV-density assessment tracker of $P$. australis condition was developed. Major findings from the use of the trajectory tool were the high decrease in HV density from 2016 to 2017, the identification of severely degraded $P$. australis marsh and European P. australis marsh in some areas, and indications of linkage between the density decline from 2016 to 2017 and the elephant-ear replacement from 2018 to 2019 . The trajectory tool application also indicated an inverse relationship between elephant-ear occurrence and HV-density changes from 2018 to 2019. A similar but weaker relationship was found between elephant-ear and LFC. These relationships may provide a means for early detection of replacement of $P$. australis marsh by elephant-ear and other unwanted plant species.

\footnotetext{
${ }^{1}$ U.S. Geological Survey.

${ }^{2}$ Cherokee Nation Technologies under contract to the U.S. Geological Survey.
}

\section{Introduction}

Recent and widespread nonnative scale insect (Nipponaclerda biwakoensi) infestation and Phragmites australis dieback has been documented in southeast Louisiana (Ramsey and Rangoonwala, 2017). Although invasive, P. australis is the dominant plant species in many southeast coastal marshes (Baurick, 2017).

P. australis marsh dieback is devastating for gulf coastal marshes because it protects them from erosion. Its height and extensive root system absorb wave impact, thus thwarting erosion and promoting land building to help stabilize coastal wetlands. Its loss is likely to spur erosion, worsening the already alarming rate of land loss (Baurick, 2017) and threatening the ecological and economic functions of the Mississippi River Delta. Loss of $P$. australis undermines the deltaic wetland support of large populations of ducks, wading birds, fish, and shellfish and the viability of Federal and State wildlife refuges that manage significant populations of wintering waterfowl. Increased erosion could clog shipping channels, posing a threat to navigation. Erosion could also expose oil and gas infrastructure, possibly leading to catastrophic loss and rupture and contamination of already degraded coastal resources.

A limited study by the U.S. Geological Survey (USGS) indicated that satellite mapping of the normalized difference vegetation index (NDVI) with satellite optical data could help track changes in $P$. australis live composition through time (Ramsey and Rangoonwala, 2017). A subsequent study by the USGS quantified the relationship between NDVI and $P$. australis live fractional cover (LFC) and used the developed relationship to map LFC yearly changes from 2009 to 2016 with Landsat and yearly plus seasonal LFC changes from 2017 to 2019 with Sentinel-2 optical image data (Rangoonwala and others, 2020). Although that LFC mapping development provides the ability to quantitatively track live composition changes relatable to the onset and progression of dieback (Ramsey and others, 2014; Ramsey and Rangoonwala, 2017), it does not directly measure another critical indicator of change, $P$. australis canopy density. As mentioned in Ramsey and Rangoonwala (2017) and Rangoonwala and others (2020), 
synthetic aperture radar (SAR) remote sensing is directly tuned to the structural aspects of the vegetation canopy, such as density (Ramsey and others, 2014, 2015, 2016).

SAR-density mapping provides an indicator of marsh thinning and heightens differences in marsh type when combined with optical mapping (Bourgeau-Chavez and others, 2009, 2013). Those enhanced capabilities should promote discernment of $P$. australis marsh dieback onset and progression and increase the ability to identify replacement by other plant species. In response to observations of replacement of P. australis by Colocasia esculenta (elephant-ear) in 2018-19 by Rangoonwala and others (2020), the USGS, in cooperation with the U.S. Fish and Wildlife Service (FWS), used SARdensity and LFC mapping to expand tracking of $P$. australis marsh changes at the FWS Delta National Wildlife Refuge (NWR) from 2016 through 2019.

\section{Purpose and Scope}

The primary purpose of this study was to develop mapping systems to identify abnormal changes in $P$. australis marsh near onset, and when identified, to use the developed mapping systems to track the detected abnormality. To assess those mapping capabilities, three study objectives were pursued. The initial objective was to use SAR mapping to document the yearly spatial $P$. australis marsh density patterns and changes in those patterns from 2016 to 2019. The second objective was to evaluate possible relationships between observed elephant-ear replacement and changes in density identified through optical-LFC and SAR-density mapping. The final objective was to assess covariance of optical LFC and SAR density as an early indicator of causal change to inform resource managers charged with mitigation efforts.

\section{Study Area}

The study area is the lower Mississippi River Delta in southeastern Louisiana (fig. 1). Within this study area, mapping efforts were focused on the FWS Delta NWR (fig. 2). Assessments and comparisons of the produced maps were also focused on the Delta NWR. P. australis marsh extent in 2016 is based on the Dugas and others (2018) mapped P. australis marsh coverage of the Delta NWR. 


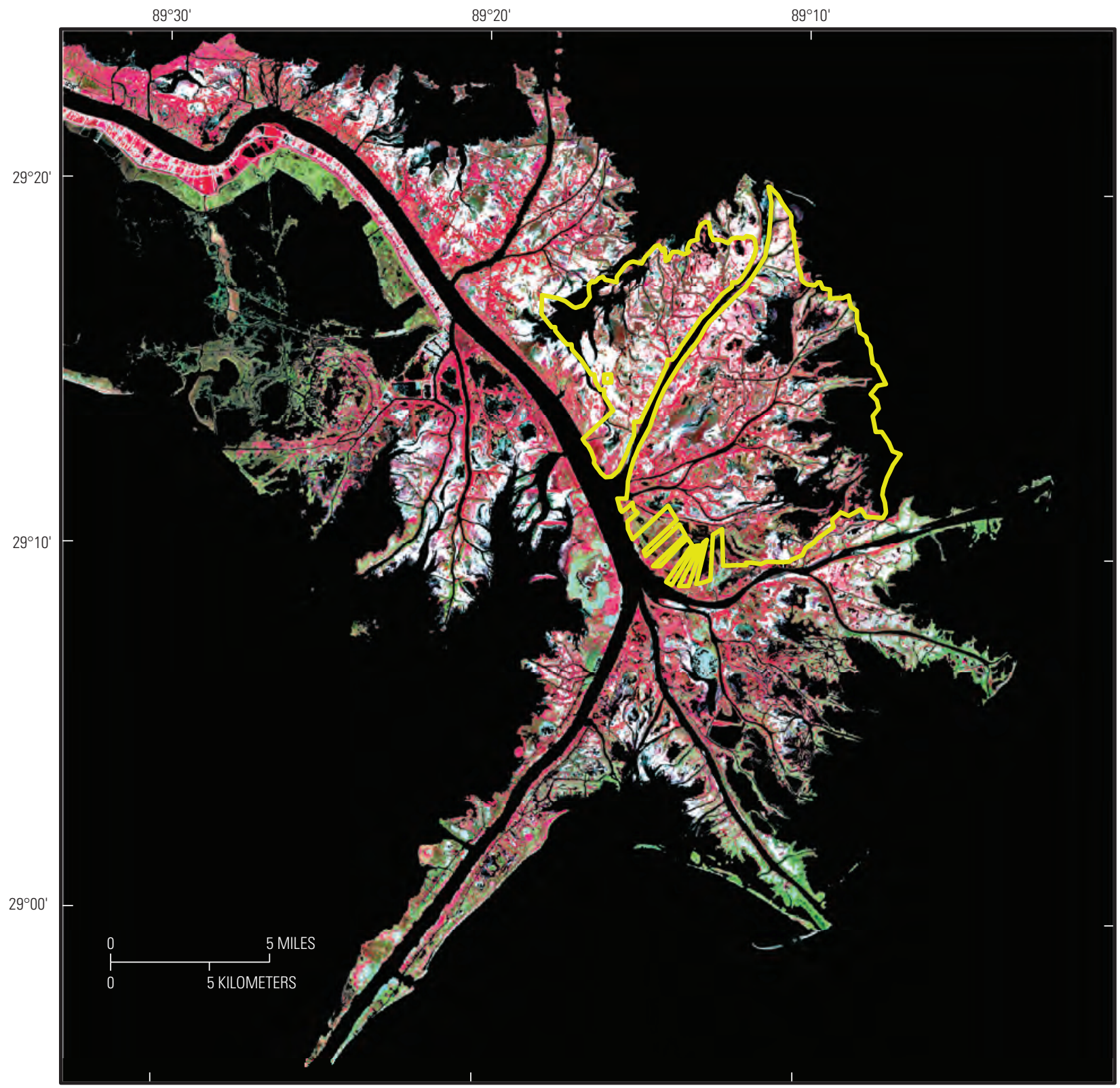

Figure 1. A Sentinel-2 optical image of the lower Mississippi River Delta study region, Louisiana, August 31, 2019. In this near-infrared, red and green band image composite, healthy vegetation tends to appear bright red. The yellow polygon outlines the U.S. Fish and Wildlife Service Delta National Wildlife Refuge.

\section{Methods}

\section{Mapping Data Sources}

\section{Satellite Optical-LFC Mapping}

Production of the LFC maps used in this study is described in Rangoonwala and others (2020). The P. australis marsh LFC status and change mapping relied on Sentinel-2 for current to future mapping and Landsat for historical mapping.

\section{Satellite SAR and $P$. australis Marsh Density}

The Advanced Land Observing Satellite (ALOS and ALOS-2, referred to as "ALOS" in this report) phased array type L-band SAR data were used for assessment of mapping $P$. australis marsh density for this study. The initiation of the SAR and optical $P$. australis marsh mapping was guided by works of Bourgeau-Chavez and others $(2009,2013)$.

In general, L-band SAR penetration into taller and denser vegetation canopies is greater than that of shorter wavelength systems (Ramsey, 1998). For this study, the higher penetration provides enhanced perception of the entire $P$. australis 


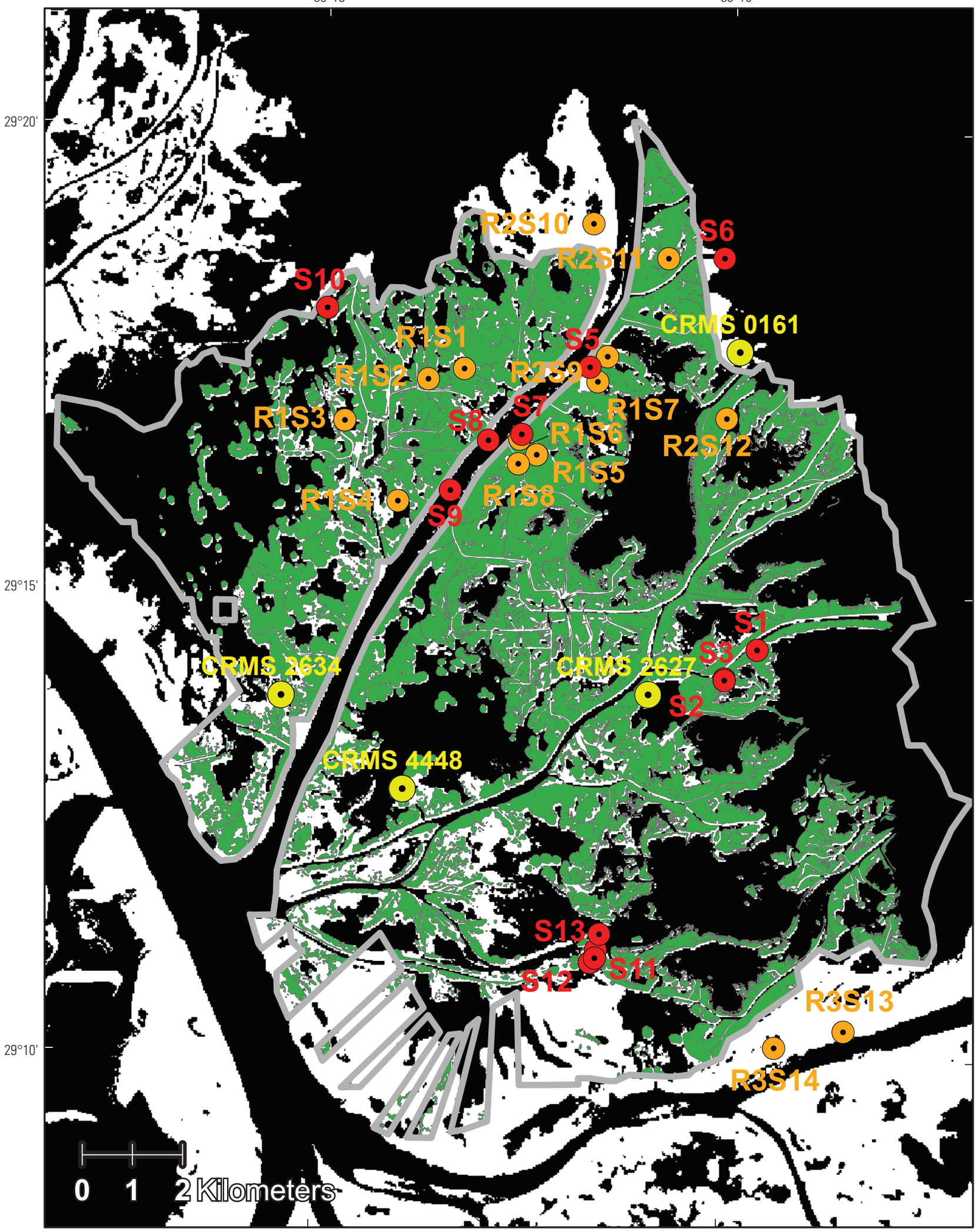

Figure 2. Phragmites australis (green) within the U.S. Fish and Wildlife Service Delta National Wildlife Refuge (gray outline) in 2016 (Dugas and others, 2018). Louisiana Coastwide Reference Monitoring System (CRMS; Coastal Protection and Restoration Authority, 2020) sites are shown in yellow (table 1), and field sites are shown in red (table 3). The regional trajectory development sites are shown in orange (table 3). 
marsh vertical profile. The cross-polarized HV (send horizontal and receive vertical polarization) or $\mathrm{VH}$ (send vertical and receive horizontal polarization) backscatter is a more sensitive indicator of vegetation volume than like-polarized $\mathrm{HH}$ (send and receive horizontal polarization) or $\mathrm{VV}$ (send and receive vertical polarization) backscatter (Ramsey, 1998; Ramsey and others, 1999, 2014). The HV backscatter based on increased penetration should be more closely aligned with the marsh density. The HV backscatter was used as the $P$. australis marsh density indicator.

\section{Production of Yearly Density-Indicator Maps from 2016 to 2018}

The ALOS SAR dual polarization HH and HV data were calibrated as sigma naught and expressed as amplitude. A 3 by 3 average filter was applied to each 6.25 -meter $(\mathrm{m})$ groundsurface-area (GSA) image to reduce speckle (BourgeauChavez and others, 2013). In only the regional site analyses, a 3 by 3 average filter was applied twice to the speckle filtered $\mathrm{HV}$ images to enhance graphical depiction of change.

ALOS SAR image coverages of the Mississippi River Delta were created for September 2016, November 2017 and 2018, and October 2019 (table 1). Coverage of the Mississippi River Delta required the composite of three SAR images. Although complete coverage of the Mississippi River Delta used SAR images from January 2017, 2018, and 2019, in the composite, the January image only covered the far eastern edge of the lower Mississippi River Delta. The composite eastern edge was not included in any comparisons or assessments. The yearly SAR HV-amplitude composites were resampled to a 10-m GSA matching Sentinel-2 and registered to Sentinel-2 images for the same year.

LFC and HV density maps were based on the months of September 2016 and October 2019 (table 1). The 2017 and 2018 late October LFC maps were also temporally comparable to the SAR maps based on early November HV-amplitude images. Although only minor senescence was expected, a decrease of canopy LFC portends lower canopy water volume, likely decreasing SAR HV amplitude (Ramsey, 1998; Ramsey and others, 2015). Due to that sensitivity, minor decreases in both LFC and SAR HV may have occurred from September to late October and early November.

Landsat LFC maps indicate an overall LFC increase from September 30, 2016, to September 17, 2017 (Rangoonwala and others, 2020). While Sentinel-2 LFC maps show a similar broad LFC increase from September 20, 2016, to October 25, 2017, these maps contain scattered pockets of LFC percent decrease within the Delta NWR (Rangoonwala and others, 2020). Sentinel-2 LFC decrease from October 30 to December 4, 2018, was higher than in 2016-17 but still lower than 20 percent. The demonstrated overall LFC stability through late October was expected to extend into early November. While the timing offset is expected to result in some seasonally related LFC change, and thereby, untraceable changes in the SAR backscatter, the resulting variability is not expected to impede the interpretability of the LFC and ALOS HV density covariance patterns.

\section{Water Mask Creation and Above-Surface Water Levels}

A water mask was created from a mix of Sentinel-2 SAR and optical images that visually best preserved $P$. australis marsh while eliminating intermittently ponded water bodies and most bare and vegetated mud flats. Except for minor edits, the same water mask was applied to all map products.

Above the marsh surface, water levels at four Coastwide Reference Monitoring System (CRMS) sites (Coastal Protection and Restoration Authority, 2020) within the Delta NWR were documented at the times of all satellite image collections (table 1). Optical remote sensing and SAR are sensitive to subcanopy flooding (Ramsey and others, 2013). Although, water levels and interior flooding vary regionally

Table 1. Surface-water levels at Louisiana Coastwide Reference Monitoring System sites in the U.S. Fish and Wildlife Service Delta National Wildlife Refuge at the times of image collections.

[CRMS, Louisiana Coastwide Reference Monitoring System (Coastal Protection and Restoration Authority, 2020)]

\begin{tabular}{llcccc}
\hline \multirow{2}{*}{ Satellite } & \multicolumn{1}{c}{ Date } & \multicolumn{3}{c}{ Water levels at CRMS sites (fig. 2), in meters above ground level } \\
\cline { 3 - 6 } & & $\mathbf{0 1 6 1}$ & $\mathbf{2 6 3 4}$ & $\mathbf{2 6 2 7}$ & $\mathbf{4 4 4 8}$ \\
\hline Sentinel-2 & September 30, 2016 & 0.321 & 0.05 & 0.181 & 0.373 \\
& October 25, 2017 & 0.129 & -0.067 & 0.096 & 0.353 \\
& October 30, 2018 & 0.083 & 0.258 & 0.361 & 0.425 \\
& October 20, 2019 & no data & 0.322 & 0.473 & 0.720 \\
\hline ALOS-2 & September 14, 2016 & 0.528 & 0.199 & 0.356 & 0.482 \\
& November 8, 2017 & 0.539 & 0.405 & 0.453 & 0.578 \\
& November 7, 2018 & 0.646 & 0.281 & 0.514 & 0.669 \\
& October 7, 2019 & 0.278 & 0.094 & 0.186 & 0.808 \\
\hline
\end{tabular}


throughout the Delta NWR, correspondence of low or high water across multiple CRMS sites indicates similarity of water levels at all sites.

\section{Site Selection and Field Data Collections}

Data were collected at sites (hereinafter referred to as "field sites") in the FWS Delta NWR during November 15-16, 2018, and August 20-22, 2019, to encompass the full range of $P$. australis growth. Sites were located beside waterways and were accessible by boat (fig. 2).

In 2018, of the 13 field sites, 10 were purely or dominantly composed of $P$. australis marsh, 1 was composed of elephant-ear, 1 was mud, and 1 was water. Of the 10 vegetation field sites in 2019, only 3 were purely or dominantly composed of $P$. australis marsh, and 7 were heavily mixed with or were purely elephant-ear. Eight of the field sites studied in 2018 were revisited in 2019. In addition, four observation sites in 2018 and five observation sites in 2019 had no instrument data collections. At all site locations, Global Positioning System coordinates and photographic and field note descriptions were obtained. At field sites, radiometer and webcam photography were collected and analyzed (Ramsey and Jensen, 1995; Rundquist and others, 2014). Radiometer data were used in the LFC mapping (Rangoonwala and others, 2020).

The webcam photography was vital for visual documentation of the percentage of elephant-ear occurrence and change from 2018 to 2019. The webcam system mounted at the same point as the radiometer obtained an approximate 4-m by 6-m red-green-blue picture of the canopy coincident with the radiometer measurement (Rangoonwala and others, 2020).

\section{Challenges in Relating Field to Satellite Measurements}

Webcam data were collected at two to three directions or locations at each field site. Although the boat platform was inserted as far as possible into the marsh and the webcam was further extended into the marsh via the support pole, all sampled locations were near the open water and marsh edge. That closeness to the edge increased the possibility of boundary pixels in the satellite images being contaminated to some extent by open water.

To lessen that possible contamination, locations where the overall marsh characteristics extended at least 2 pixels, or $20 \mathrm{~m}$, beyond the edge into the interior were preferred for data collection. While that criterion tended to minimize edge-pixel contamination, variable water levels increased the variance of the satellite measurements. Further, variability of each individual pixel composition was caused by georeferencing in optical and SAR images and by resampling and filtering of the SAR images; this variability taxed the analyses applied in this study based on single pixel correspondences.

\section{HV, LFC, and Elephant-Ear Graphical Comparisons}

Elephant-Ear Increase and HV and LFC Response

In 2018 and 2019, percentages of elephant-ear coverage at field sites were estimated by visual inspection of field webcam photography (fig. 3). HV and LFC magnitudes were extracted from 2018 and 2019 SAR HV and LFC collocated field sites. Scatterplots were used to inspect the covariance of HV and LFC change with change of elephant-ear from 2018 to 2019. The change plots were used to remove variability in the starting values, and in this case, localize the dependent response to the independent change to a single year.

\section{Fused HV-Density and Optical-LFC Trajectory Status Monitors}

Temporal HV-LFC trajectory plots were used to enhance tracking of change, in this case, change in $P$. australis marsh. The trajectory plots provide three-dimensional (HV, LFC, time) transition patterns that reveal changes, such as growth, degradation, regrowth, or replacement, that are unlikely to be noticed on one-dimensional status or change maps unless change is dramatic.

\section{Field Site Trajectory Plots}

Trajectory plots were used to inspect the covariance of HV and LFC magnitudes extracted from 2016, 2017, 2018, and 2019 ALOS HV and LFC collocated field sites. These trajectory plots incorporate the 2018 and 2019 field-observed $P$. australis condition. Due to the field sampling logistics, these sites represent berms along canal edges. The 2018 and 2019 field observations indicated that higher $P$. australis marsh densities occur on the berms while lower densities occupy the intervening basins.

\section{Regional Site Trajectory Plots}

To include basin P. australis marsh trajectories, an HV color composite was created for 2016-18. The HV color composite was combined with the LFC color composite (Rangoonwala and others, 2020) and was used to select regional trajectory sites within three Delta NWR regions (fig. 2) based on hue and tonal differences. The tonal differences were expected to reflect variation of $P$. australis marsh trajectories over the 3 years. The inclusion of basin sites broadens the scope of the $P$. australis marsh trajectory analysis and contrasts differences in berm-basin LFC and HV density.

Fifteen sites (hereinafter referred to as "regional sites") were chosen from 3 regions in the Delta NWR (fig. 2), and LFC and HV image data for 2016, 2017, 2018, and 2019 were extracted from the 3- by 3-pixel area encompassing 

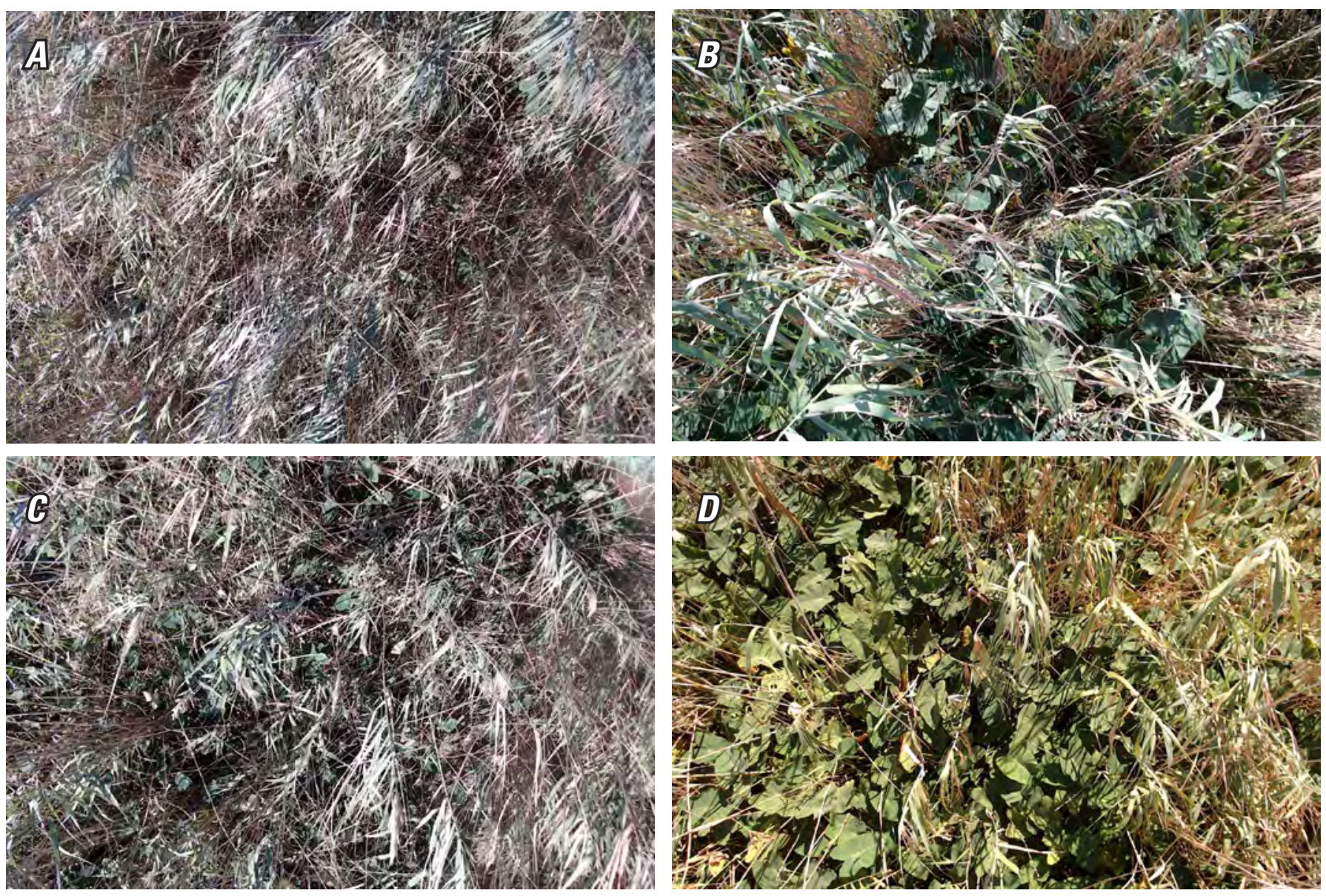

Figure 3. Webcam photographs of two field sites: $A$, site $\mathrm{S} 1,2018 ; B$, site $\mathrm{S} 1,2019 ; C$, site $\mathrm{S} 3,2018$; and $D$, site $\mathrm{S} 3$, 2019 (fig. 2, table 3). Increased elephant-ear cover is seen at both field sites.

each site's central coordinate. Eleven of the 15 sites were in $P$. australis marsh exhibiting different hues and in different types of locations, such as along waterways, in basins between waterways, and in the eastern extent of the Delta NWR. Site R3S13 of region 3 (fig. 2) was in European P. australis marsh (Knight and others, 2019) just outside the southern extent of Delta NWR.

\section{Results}

\section{ALOS HV-Density-Indicator Mapping}

The HV densities were mapped for 2016, 2017, 2018, and 2019 (fig. 4). The gray shading indicates the HV amplitude; the higher the HV amplitude, the lighter the gray shading. The most striking features within all four maps are the relatively high amplitudes, or $P$. australis marsh densities, lining the waterways and the low amplitudes in the interceding basins. Higher amplitudes are seen toward the western Delta NWR, particularly in 2018 (fig. 4C). The next notable contrast is the overall lower amplitudes, or lower P. australis marsh densities, in 2017; most apparent in comparison to HV amplitudes in 2018. A 2016 (red), 2017 (green), and 2018 (blue) HV image composite shows the spatial variation of marsh density among the 3 years (fig. 5).

As in the LFC maps of Rangoonwala and others (2020), hue and tonal differences represent variation in the yearly combination of $\mathrm{HV}$ amplitudes, or $P$. australis marsh densities (fig. 5). In contrast to the Delta NWR LFC composite depiction (Rangoonwala and others, 2020), the HV-density amplitude composite exhibits larger areas of uniformity and overall, less heterogeneity. In figure 5, the higher densities are most often represented by oranges, pinks, and off-whites. Orange represents higher $2016 \mathrm{HV}$ amplitudes, indicating higher P. australis marsh densities, mixed with equally low 2017 and 2018 HV amplitudes, or lower P. australis densities. Pink indicates that $2016 \mathrm{HV}$ amplitudes are higher than in 2017 and 2018, and white indicates that 2016 and 2018 HV amplitudes are nearly equal and high and that $2017 \mathrm{HV}$ amplitudes are slightly lower than 2017 and 2018 amplitudes. Greenish hues indicate overall moderate but slightly higher densities in 2017.

P. australis marsh occupying basins lying between canals and waterways have low HV amplitudes reflecting generally low P. australis marsh densities. Subtle changes of green, red, 

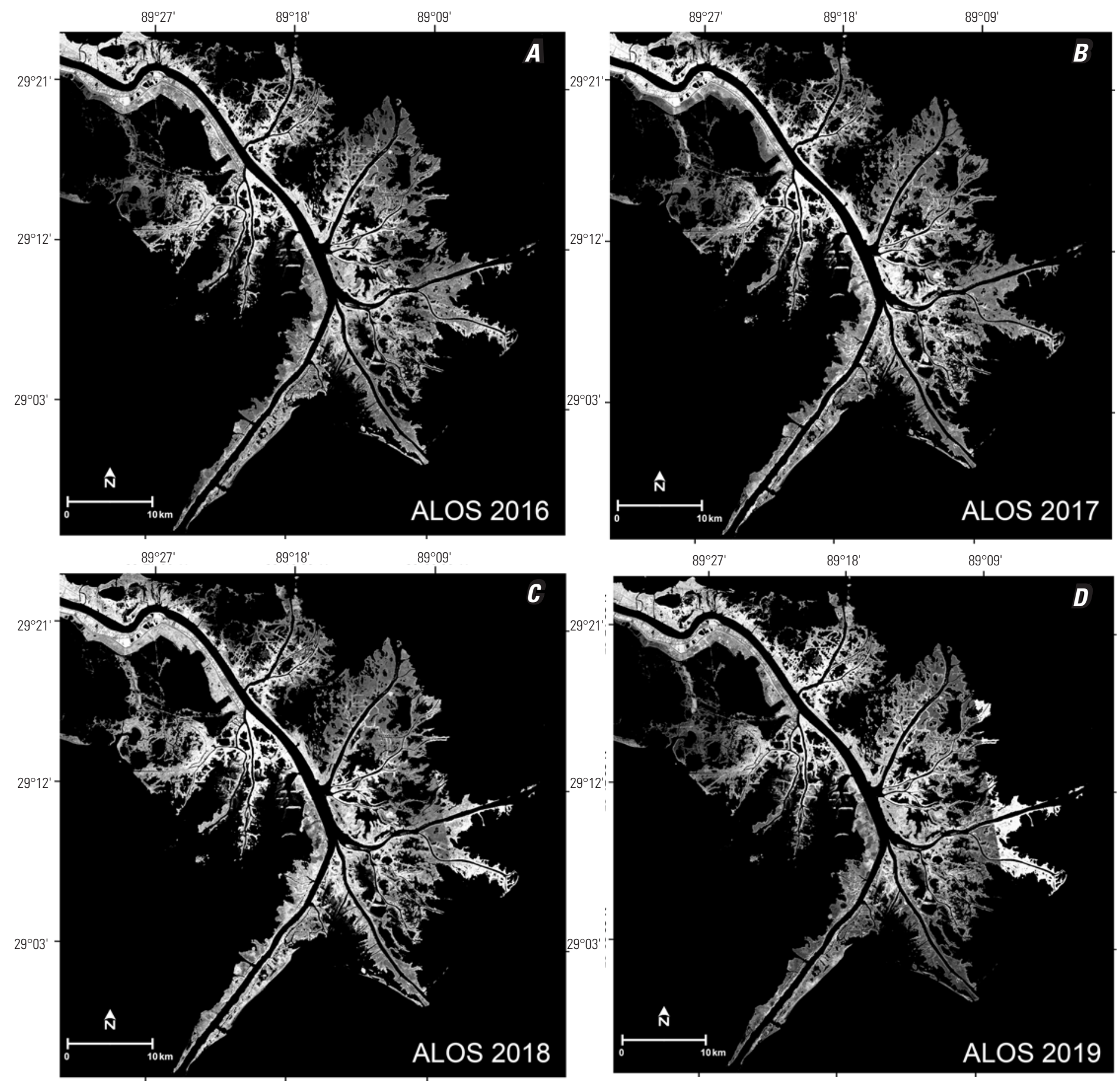

Figure 4. Composited Advanced Land Observing Satellite (ALOS) synthetic aperture radar HV images. A, 2016, B, 2017, C, 2018, and D, 2019. Lighter gray indicates higher HV amplitudes, and darker gray indicates lower HV amplitudes. The gray shading is directly comparable among all four images. 


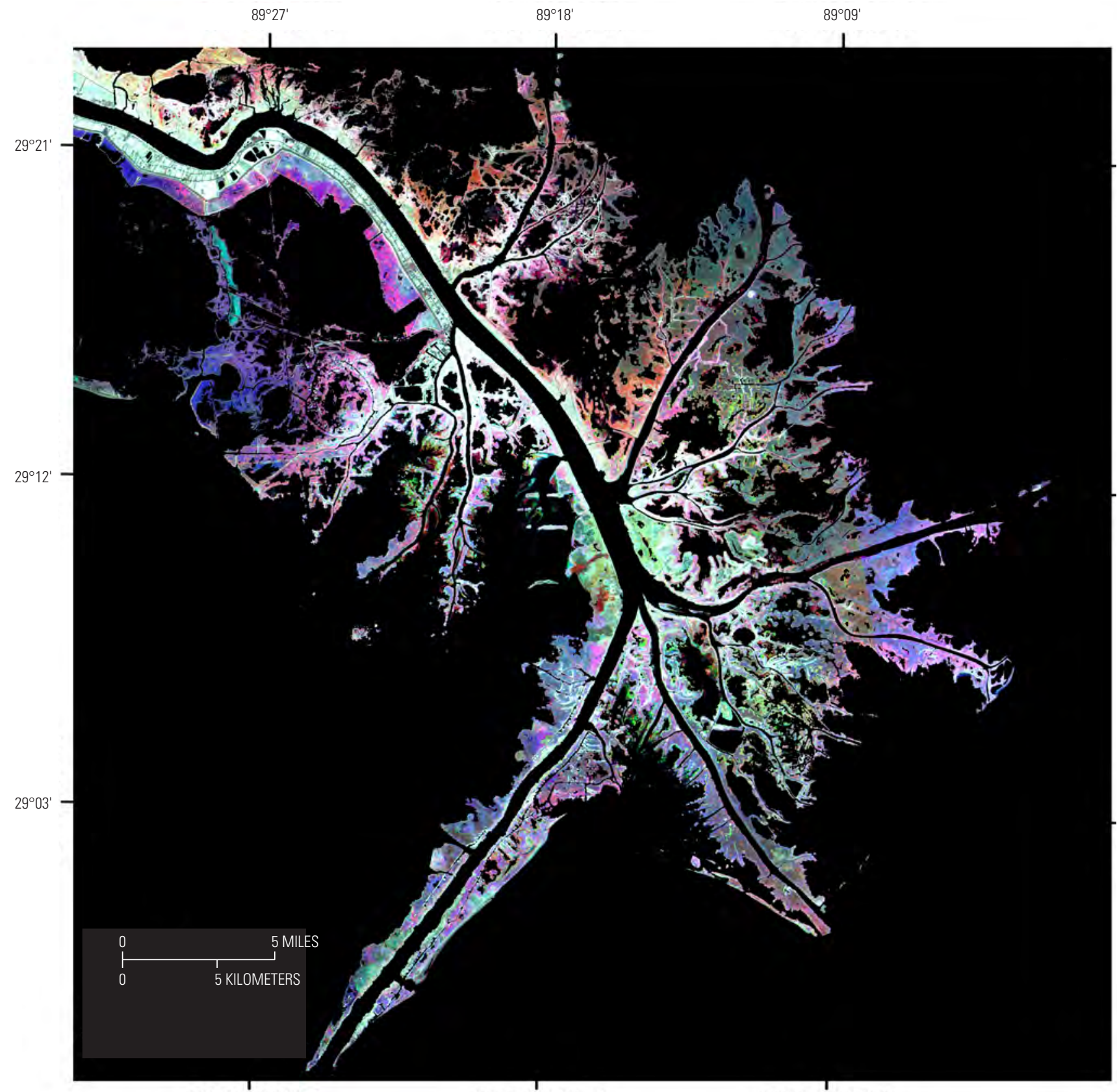

Figure 5. Advanced Land Observing Satellite-2 HV color composite displaying the $2016 \mathrm{HV}$ amplitude as red, $2017 \mathrm{HV}$ amplitude as green, and $2018 \mathrm{HV}$ amplitude as blue. The same HV-magnitude color rendition was used for all 3 years.

and blue hues in images of these marshes represent slight variability in the marsh density from year to year. Some images of areas in the northeast part of Delta NWR exhibit more vivid hues indicating a somewhat elevated density contrast between years. Low differences between years were also exhibited in the LFC composite within the eastern Delta NWR
(Rangoonwala and others, 2020). In fact, similar features shown in the LFC composite and HV composite indicate changes in density. A comparison of selected common regions outlined on the LFC and HV composites helps elucidate the covariance of LFC and density in the P. australis marsh. 


\section{LFC and HV-Density Comparison}

\section{8 and 2019 Field Site Comparison}

\section{HV Related to LFC}

Although point scatter was high as indicated by the high standard error (SE) associated with the regression intercepts, the covariances exhibited by HV and LFC within 2018 and separately within 2019 and between 2019 and 2018 are highly significant $(\leq 0.0007)$ (table 2$)$. The regressions for 2018 and 2019 exhibit a positive linear increase in HV with LFC. The 2019 and 2018 HV regression slope depicts a positive linear relationship close to 1 , and the intercept indicates that $\mathrm{HV}$ magnitudes were clearly higher in 2019 than in 2018 (table 2).

\section{Elephant-Ear Increase Related to HV and LFC}

The regressions between elephant-ear and $\mathrm{HV}$, and particularly elephant-ear and LFC, contained scatter that could not be conclusively accounted for. The variability in the alignment of the image pixel, especially after necessary post-processing for spatial alignment and scale and noise, was expected to be at times high at the single pixel level. Our decision was to highlight the dominant trend by eliminating sites exhibiting little relevance to that trend. In this regard, the noted trends are based on a reasonable expectation but are still subjective. With that interpretation caveat, the 2019-2018 elephant-ear versus 2019-2018 HV difference plot clearly exhibits a linear decrease of $\mathrm{HV}$ with increase of elephant-ear percentage (fig. 6A). Although high scatter weakens trend clarity, elephantear tends to increase as LFC decreases (fig. 6B).

\section{Trajectory Descriptions and Comparisons}

\section{Field Trajectory Descriptions and Comparisons}

Along with HV and LFC dataset pairs from field sites occupied in 2018 and 2019, similar datasets were incorporated from 2016 to 2017 in the trajectory analysis. Graphic portrayals depict the trajectory pattern of selected field sites (fig. 7), and normalized and tabulated year-to-year HV and LFC differences expose yearly patterns, groupings, and anomalies (table 3).
A common pattern in the HV and LFC differences is the 2016 to 2017 high decrease of HV amplitude, averaging $74 \pm 22$ percent $(n=8)$ at all field sites. Also noticeable is that while the HV consistently exhibited substantial decreases, 2016 to 2017 LFC differences were mixed, averaging $-2 \pm 39$ percent, a value suggesting high variability in overall LFC change. From 2017 to 2018, positive changes at all sites resulted in an

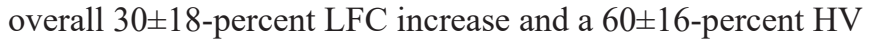
increase from 2017 to 2018. From 2018 to 2019, decreases at sites S6, R1S2, and R1S7 resulted in a low overall LFC increase of $6 \pm 24$ percent. Moderate to low increases characterized $\mathrm{HV}$ sites, leading to an overall increase of $34 \pm 21$ percent from 2018 to 2019.

\section{Regional Trajectory Descriptions and Comparisons}

The 2016, 2017, and 2018 HV color-composite image (fig. 5) was combined with the LFC color composite image from Rangoonwala and others (2020) for selection of regional trajectory sites from the three regions shown in figure 2 (figs. 8 and 9). Trajectory plots constructed from LFC and HV extracted from each of the 14 regional sites for 2016, 2017, 2018, and 2019 were plotted and normalized differences were tabulated (table 3, fig. 10). As in the field trajectory workup, the most striking feature of the plots was change. At 12 of the 15 regional sites, change was noted between 2016 and 2017 , between 2017 and 2018, and between 2018 and 2019. At the remaining three regional sites (sites R1S3, R2S9, and R3S13), change was notable only between one or two time periods. Secondly, $P$. australis berm HV magnitudes (regional sites R1S2, R1S3, and R1S6) were substantially higher than basin magnitudes as noted in the axes' scales (figs. $10 B, C$, and $E$ ). On average, the berm sites had somewhat higher LFC and substantially higher HV-density ranges than basin sites. Thirdly, the berm sites exhibited a high decrease of HV density from 2016 to 2017, and even though of lower magnitudes, relatively substantial decreases occurred at 6 of the 12 basin sites (sites R1S4, R1S5, R1S8, R2S10, R3S13, and R3S14). At the four remaining $P$. australis regional sites (sites R1S1, R2S9, R2S11, R2S12), HV density did not change much from 2016 to 2017.

Table 2. Simple regressions describing HV and LFC relationships.

[SE, standard error; $\mathrm{R}^{2}$, regression coefficient; obs, observations; model $\mathrm{p}>\mathrm{F}$, regression model; $\mathrm{p}, \mathrm{p}$ value; $>$, greater than; F, F statistic; HV, horizontal send, vertical receive; LFC, live fractional cover]

\begin{tabular}{llllcrr}
\hline \multicolumn{1}{c}{ Regression } & \multicolumn{1}{c}{ Dependent } & Intercept (SE) & Slope (SE) & $\mathbf{R}^{\mathbf{2}}$ & obs & model p>F \\
\hline 2018HV_2018LFC & $2018 \mathrm{HV}$ & $400.5(148.7)$ & $6.1(1.4)$ & 43.4 & 27 & 0.0002 \\
2019HV_2019LFC & $2019 \mathrm{HV}$ & $471.3(176.1)$ & $9.1(1.4)$ & 61.6 & 27 & $<0.0001$ \\
2019HV_2018LFC & $2019 \mathrm{HV}$ & $35.3(196.5)$ & $14.4(1.8)$ & 71.3 & 27 & 0.0001 \\
2019HV_2018HV & $2019 \mathrm{HV}$ & $358.3(309.6)$ & $1.1(0.3)$ & 37.7 & 27 & 0.0007 \\
2019LFC_2018LFC & 2019LFC & $-4.2(19.3)$ & $1.2(0.2)$ & 62.2 & 27 & $<0.0001$ \\
\hline
\end{tabular}


$\boldsymbol{A}$

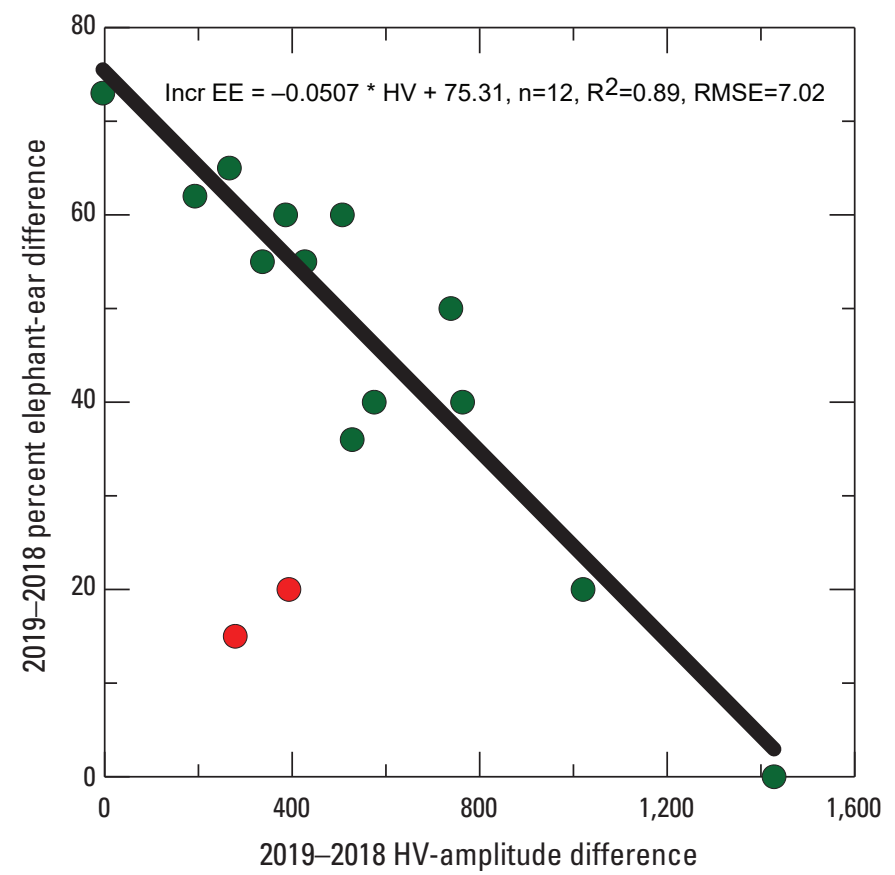

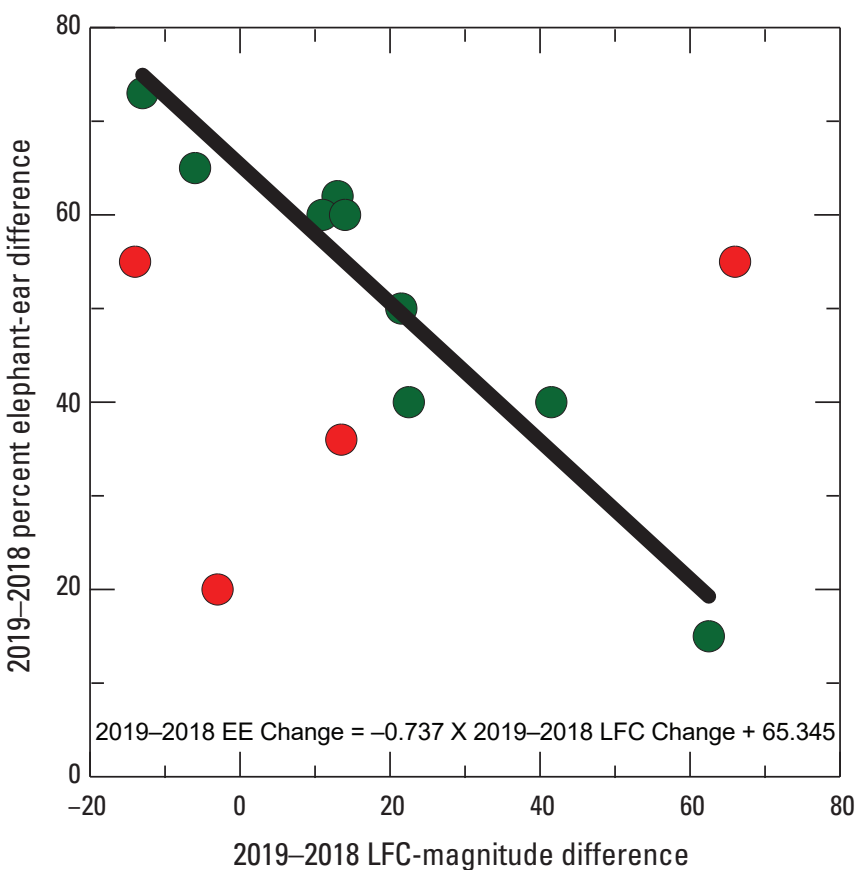

Figure 6. The 2019 minus 2018 elephant-ear (EE) difference compared to the 2019 minus $2018(A)$ HV-amplitude and $(B)$ live fractional cover (LFC) differences at berm sites (fig. 2; table 3). Sites shown with green symbols were used in the regression, and sites shown with red symbols were not. [RMSE, root-mean-square error]

\section{Discussion}

Yearly maps of the lower Mississippi River Delta from 2016 to 2019 of L-band SAR HV indicated that $P$. australis marsh density was highest along waterways and lowest within the intervening basins. HV mapping also indicated that the $P$. australis marsh density was highly heterogeneous. Opticalbased maps of LFC exhibited similar patterns of variability (Rangoonwala and others, 2020).

The overall HV, as a density indicator, and LFC correspondence was confirmed in regressions including $\mathrm{HV}$ and LFC data from field site locations for 2018 and 2019. All between- and within-year correspondences were positive and significant $(\mathrm{p} \leq 0.0007)$; however, point scatter was high, indicating high local variance. The similar patterns of mapped and plotted HV density and LFC overall correspondence, while exhibiting high local variability, led to inspection of the $\mathrm{HV}$ and LFC local variability as an enhanced mechanism for tracking $P$. australis change.

The two-dimensional HV and LFC time-sequence plot is effective for highlighting change as well as showing the nature of the change; HV supplies the density, and LFC supplies the live composition information. HV changes are exhibited along one dimension, and LFC changes are exhibited along the orthogonal dimension. The HV-LFC trajectories document biophysical movement while retaining the capability of showing the density and live composition of the P. australis marsh.
Trajectory plots from 2016 to 2019 represented 2018 and 2019 calibration field sites located on berms and noncalibration regional sites primarily located in basins. Unless noted, all sites were located in $P$. australis marsh as defined by a 2016 classification of the Delta NWR (Dugas and others, 2018). Onsite observations in 2018 and 2019 at all field sites and during one or both years at more than half of the regional sites documented the nature of the 2018 and 2019 transitions. Trajectories show that 6 of the 8 berm field sites and 4 of the 10 basin regional sites exhibited full P. australis recovery (density and LFC) by 2019 after the decreases from 2016 to 2017.

The common trajectory feature for all eight field sites is the large decrease in HV density from 2016 to 2017 that often accompanied a mixed LFC response. Although trajectories for field sites differed, following those decreases, HV density and LFC mostly recovered or exceeded the 2016 magnitudes by 2019. At three of the five marsh field sites that were pure $P$. australis in 2018 (sites $\mathrm{S} 1, \mathrm{~S} 5, \mathrm{~S} 9$ ), that $P$. australis recovery included elephant-ear or weed partial replacement by 2019. Of the two remaining pure $P$. australis field sites (sites S6, S8), site S6 is located on the edge of the Gulf of Mexico and experiences a high frequency of flushing, which may sustain the pure monoculture. The second (site S8) is located near another field site (S9) that was also pure P. australis marsh in 2018 but had considerable weed replacement in 2019. Until 2019 , the only substantial difference between the S8 and S9 sites was the much lower $2016 \mathrm{HV}$ and LFC magnitudes 
Table 3. Mid-range normalized HV and LFC differences between years at field sites and regional sites at the U.S. Fish and Wildlife Service Delta National Wildlife Refuge, 2016-19.

[Sites described as "not observed" were not visited in 2018 or 2019. Sites described as "not classified" were not included in the classification from Dugas and others (2018). LFC, live fractional cover; HV, horizontal send, vertical receive; P. australis, Phragmites australis. LFC values calculated from maps contained in Rangoonwala and others (2020)]

\begin{tabular}{|c|c|c|c|c|c|c|c|}
\hline \multirow{2}{*}{$\begin{array}{l}\text { Site identifier } \\
\quad \text { (fig. 2) }\end{array}$} & LFC & HV & LFC & HV & LFC & HV & \multirow{2}{*}{ Site description } \\
\hline & \multicolumn{2}{|c|}{ 2017-2016 } & \multicolumn{2}{|c|}{ 2018-2017 } & \multicolumn{2}{|c|}{ 2019-2018 } & \\
\hline \multicolumn{8}{|c|}{ Field sites (berm sites) occupied in 2018 and 2019} \\
\hline S1 & 75 & -112 & 5 & 65 & 52 & 36 & $\begin{array}{l}\text { P. australis site in 2018; mixed } P \text {. australis and } \\
\text { elephant-ear site in } 2019 \text {. }\end{array}$ \\
\hline S2 & -38 & -96 & 33 & 88 & 2 & 13 & $\begin{array}{l}\text { Disturbed } P \text {. australis and elephant-ear site in 2018; } \\
\text { increased elephant-ear in } 2019 .\end{array}$ \\
\hline S3 & 5 & -67 & 20 & 37 & 4 & 27 & $\begin{array}{l}\text { Low P. australis and high elephant-ear in } 2018 \text {; } \\
\text { increased elephant-ear in } 2019 \text {. }\end{array}$ \\
\hline S5 & -18 & -44 & 17 & 61 & -9 & 35 & $\begin{array}{l}\text { P. australis site in 2018; mixed } P \text {. australis and } \\
\text { elephant-ear site in } 2019 \text {. }\end{array}$ \\
\hline S6 & 35 & -67 & 12 & 49 & -38 & -1 & Eastern fringe P. australis site in 2018 and 2019. \\
\hline S7 & 0 & -93 & 52 & 79 & 4 & 42 & $\begin{array}{l}\text { Elephant-ear site in 2018; increased elephant-ear in } \\
2019 .\end{array}$ \\
\hline S8 & -20 & -51 & 48 & 63 & 20 & 74 & P. australis site in 2018 and 2019 . \\
\hline S9 & -56 & -59 & 53 & 41 & 16 & 47 & $\begin{array}{l}\text { P. australis site in 2018; mixed P. australis and weeds } \\
\text { in } 2019 \text {. }\end{array}$ \\
\hline \multicolumn{8}{|c|}{ Regional sites (All basin sites except those identified as berm sites or tree stand) } \\
\hline R1S1 & 7 & 43 & -16 & 5 & -1 & 2 & Not observed. Classified P. australis in 2016. \\
\hline R1S2 & -30 & -92 & 34 & 13 & -74 & 17 & Berm: Not observed. Classified P. australis in 2016. \\
\hline R1S3 & 14 & -124 & -3 & 24 & -26 & 54 & Berm: Not observed. Classified P. australis in 2016. \\
\hline R1S4 & -23 & -83 & -161 & 36 & 166 & 60 & $\begin{array}{l}\text { Not observed. Classified P. australis in 2016. Not } \\
\text { shown in figure } 10 .\end{array}$ \\
\hline R1S5 & -38 & -65 & 7 & 45 & 6 & 3 & $\begin{array}{l}\text { Observed edge } 2018 \text { and 2019. Increasing elephant- } \\
\text { ear subcanopy. }\end{array}$ \\
\hline R1S6 & -2 & -106 & 16 & 40 & 15 & 53 & $\begin{array}{l}\text { Berm: Observed } 2018 \text { and 2019. No P. australis; } \\
\text { increasing elephant-ear. }\end{array}$ \\
\hline R1S7 & -30 & -32 & 40 & 7 & -65 & 24 & Observed 2018 and 2019. Tree and shrub stand. \\
\hline R1S8 & -6 & -88 & -39 & 51 & 29 & 10 & $\begin{array}{l}\text { Observed edge } 2018 \text { and 2019. Mix with increasing } \\
\text { elephant-ear in } 2019 .\end{array}$ \\
\hline R2S9 & -4 & -16 & -22 & 23 & 1 & -8 & Observed 2019. High mix of woody and grass types. \\
\hline $\mathrm{R} 2 \mathrm{~S} 10$ & -63 & -41 & -20 & 39 & 35 & 2 & $\begin{array}{l}\text { Not observed and not classified in 2016. Not shown } \\
\text { in figure } 10 .\end{array}$ \\
\hline $\mathrm{R} 2 \mathrm{~S} 11$ & 21 & 9 & -6 & 39 & -18 & -39 & Observed. Plants, shrubs, grasses. Eastern fringe site. \\
\hline $\mathrm{R} 2 \mathrm{~S} 12$ & 10 & -14 & -33 & 32 & 25 & -36 & $\begin{array}{l}\text { Observed at distance. Degrading P. australis eastern } \\
\text { fringe. }\end{array}$ \\
\hline $\mathrm{R} 3 \mathrm{~S} 13$ & -11 & -98 & 5 & 34 & 0 & -8 & $\begin{array}{l}\text { Not observed. Site referenced in Knight and others } \\
\text { (2019). }\end{array}$ \\
\hline $\mathrm{R} 3 \mathrm{~S} 14$ & 26 & 52 & -13 & 15 & -24 & -44 & Not observed and not classified in 2016. \\
\hline
\end{tabular}



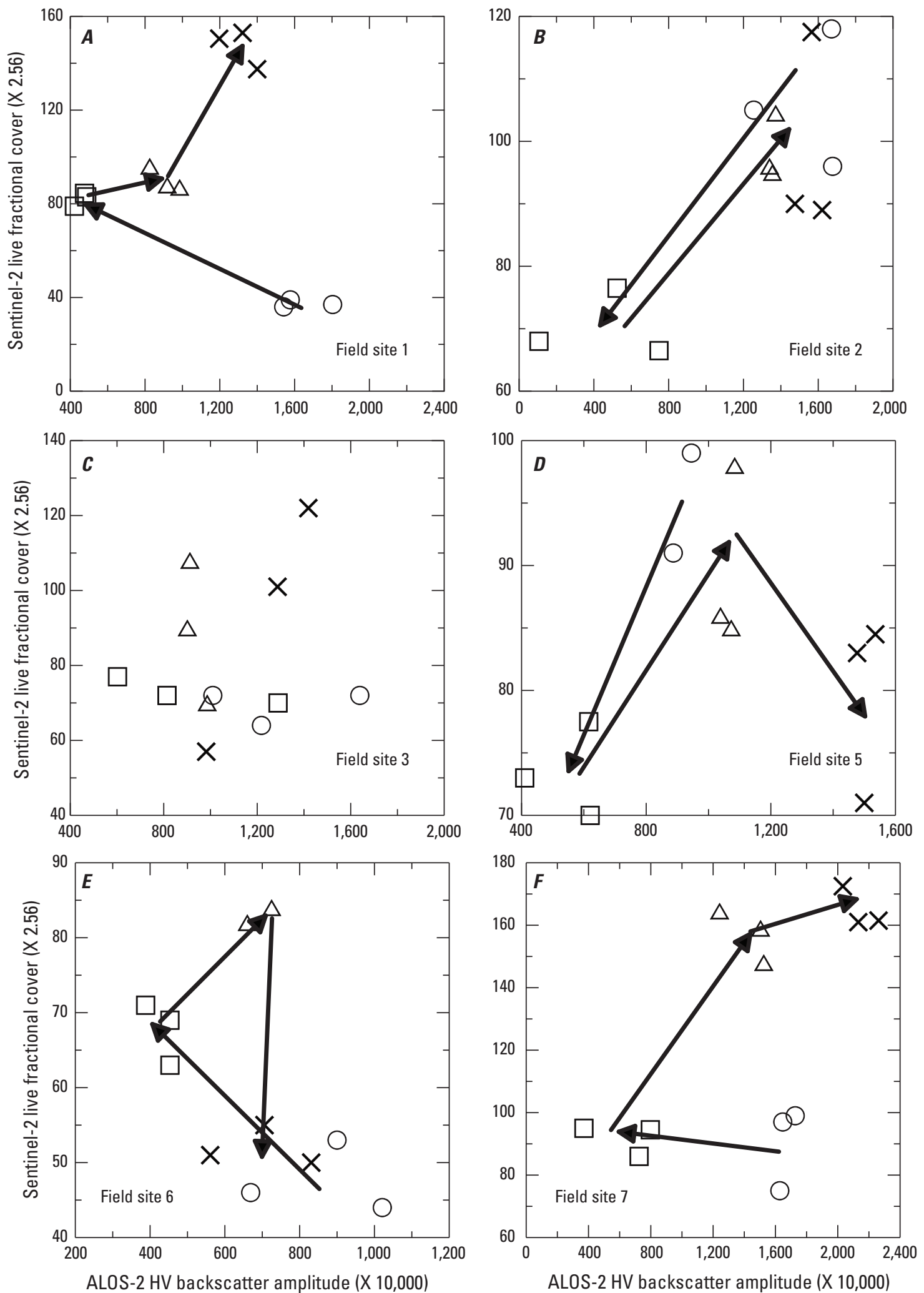

Figure 7. Trajectories for Sentinel-2 live fractional cover and Advanced Land Observing Satellite-2 (ALOS-2) HV amplitudes for field sites, 2016-19 (table 3). On graphs circles signify 2016 data, squares 2017 data, triangles 2018 data, and crosses 2019 data. Note: The graph for field site 3 does not have trajectory arrows because a pattern was unclear. 

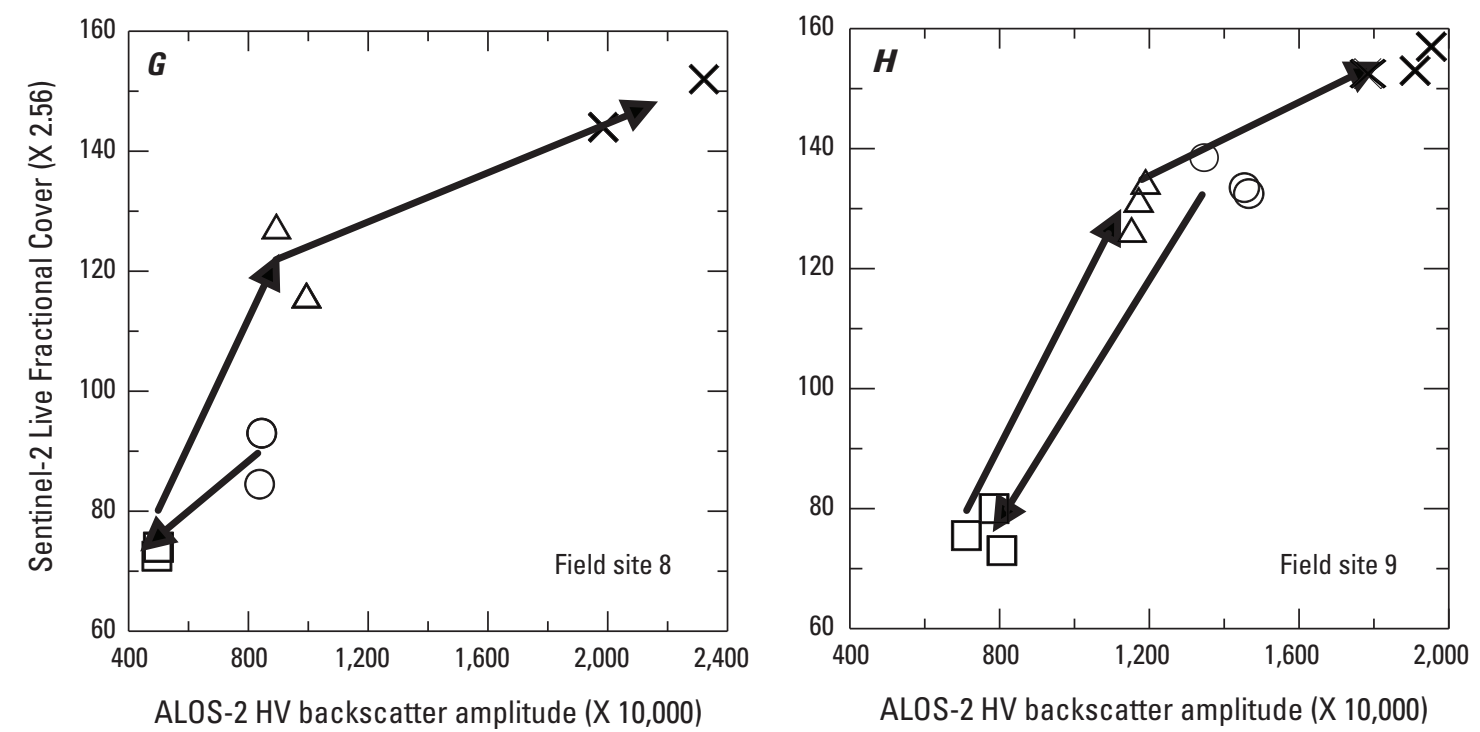

Figure 7.-Continued
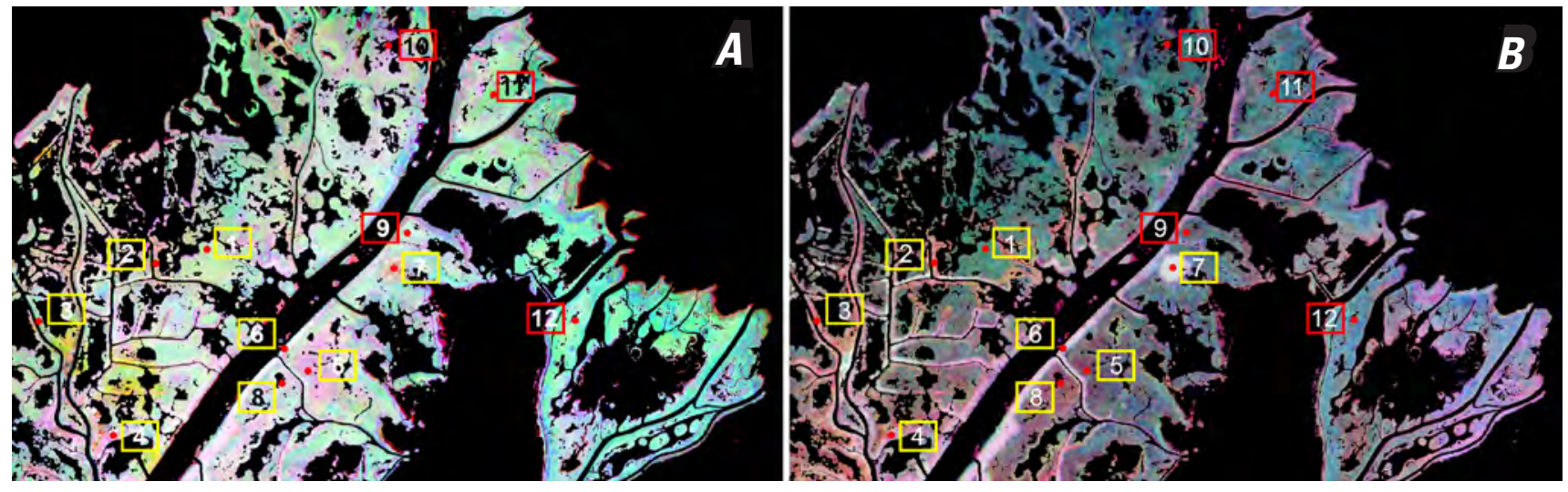

Figure 8. (A) Sentinel-2 composite image showing live fractional cover for 2016, 2017, and 2018. (B) Advanced Land Observing Satellite-2 composite image showing HV amplitudes for 2016, 2017, and 2018. Sites in region 1 are outlined in yellow; sites in region 2 are outlined in red (all sites shown in orange in fig. 2).
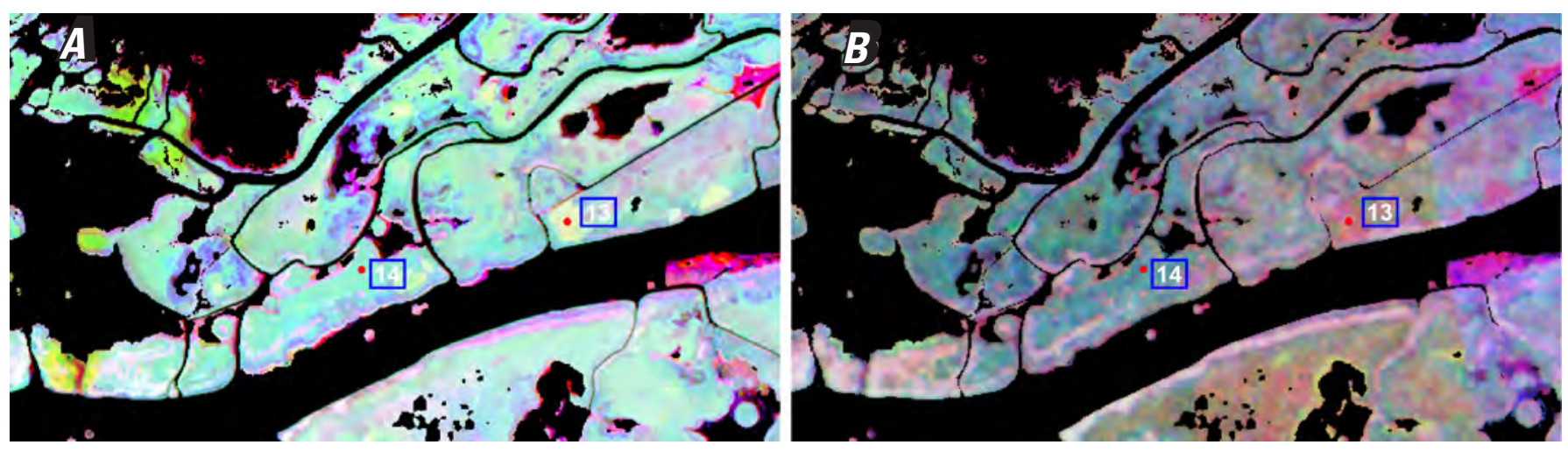

Figure 9. (A) Sentinel-2 composite image showing live fractional cover for 2016, 2017, and 2018. (B) Advanced Land Observing Satellite-2 composite image showing HV amplitudes for 2016, 2017, and 2018. Sites shown are in region 3 (shown in orange in fig. 2). 

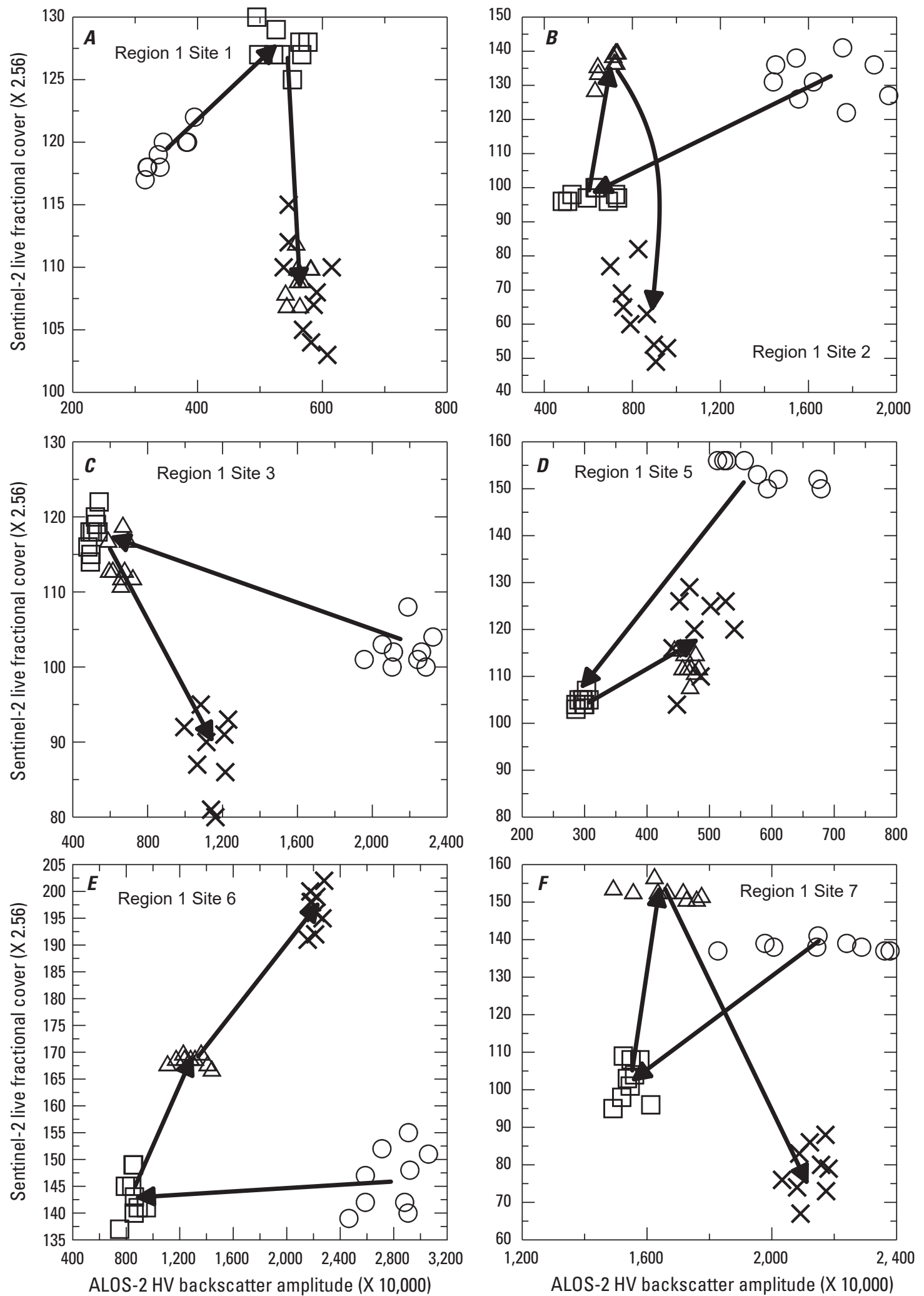

Figure 10. Trajectories for Sentinel-2 live fractional cover and Advanced Land Observing Satellite-2 (ALOS-2) HV backscatter amplitudes for regional sites, 2016-19 (table 3). [Circles signify 2016 data, squares 2017 data, triangles 2018 data, and crosses 2019 data] 

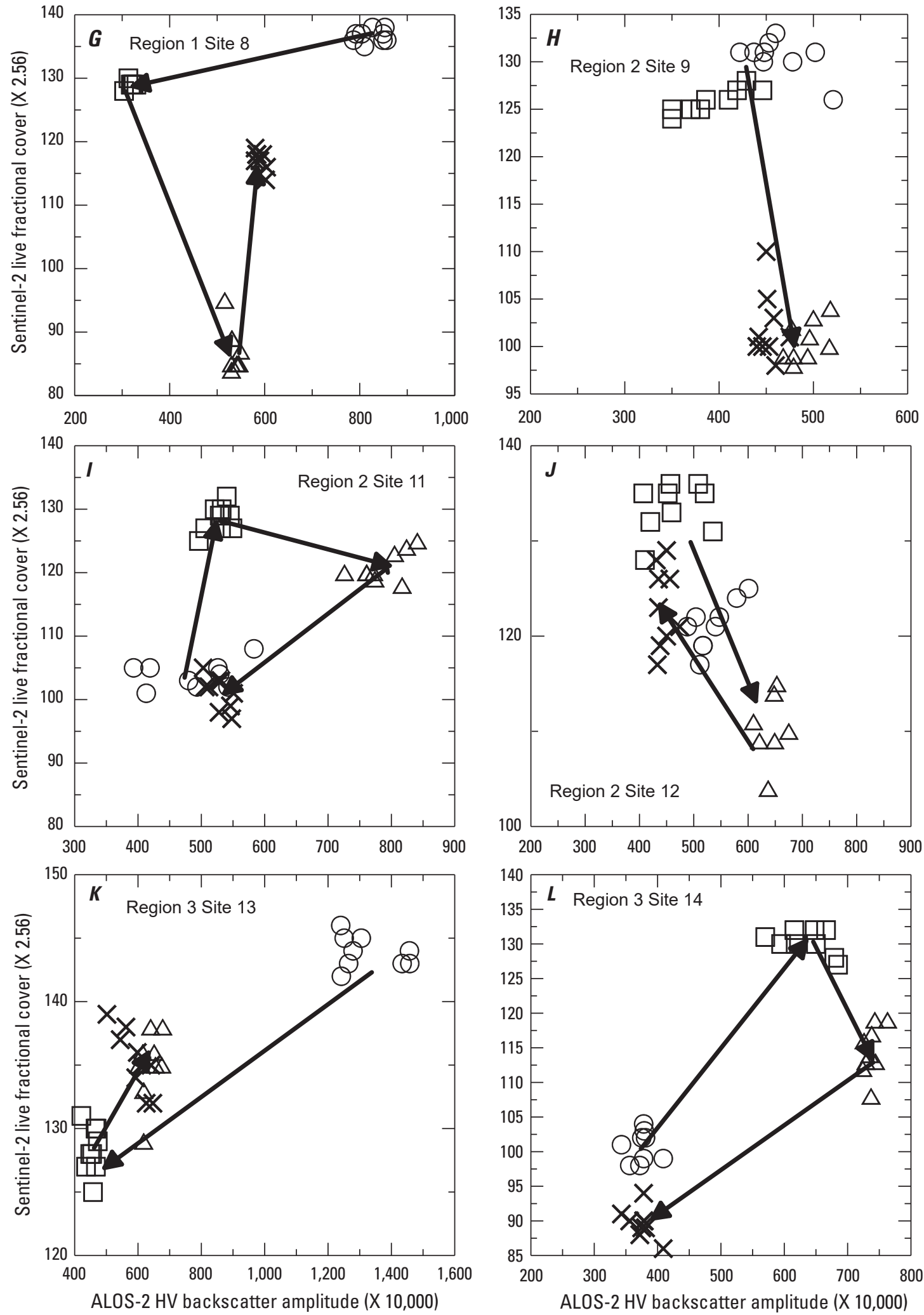

Figure 10.-Continued 
at the S8 site relative to S9. That observed single incidence does not confirm the 2016 to 2017 dieback as related to the increased replacement of $P$. australis by weeds and elephantear in 2019. That observation does, however, show the power of the trajectory tool to advance the understanding of $P$. australis response to causal agents of change and dramatically advance early identification of adverse change.

At the field sites that were composed of $P$. australis and elephant-ear or pure elephant-ear in 2018 (sites S2, S3, S7), elephant-ear had dramatically increased in size (height and width) by 2019. At the field sites that were composed of mixed P. australis and elephant-ear in 2018 (sites S2, S3), elephantear increased in cover by 2019 . The elephant-ear growth spurt is likely related to the elephant-ear replacement of $P$. australis marsh from 2018 to 2019.

From 2016 to 2017, HV and LFC decreased at five of the nine regional basin sites (R1S4, R1S5, R1S8, R2S10, R3S13), increased at three sites (R1S1, R2S11, R3S14), and remained largely unchanged at site R2S12. Two of the basin sites (sites R1S5, R1S8) exhibiting decrease were observed as mixed $P$. australis sites in 2018, with increasing elephant-ear replacement in 2019. Additional basin sites exhibiting increase were located at the northeastern extreme of the Delta NWR boundary. At one of these sites (R2S11), direct observation in 2019 revealed that the region has converted to a mixture of shrubs and plants with little or no P. australis. Another of these sites (R2S12) was reported to be highly degraded.

In addition to revealing changing compositions solely related to 2016 to $2018 \mathrm{HV}$-density and LFC changes, the full 2016 to 2019 regional trajectories identified non- $P$. australis marsh (fig. 10). Observations in 2019 confirmed that the abnormal trajectory pattern for site R1S7 indicated a stand of trees and shrubs, and observations at site R1S9 confirmed a variable mix of vines, plants, and sparse $P$. australis. The abnormal trajectory for site R3S13 revealed a stand of European P. australis. That stand experienced extreme loss of density and moderate loss of LFC from 2016 to 2017 and showed little recovery through 2019 . This variety of $P$. australis marsh is easily discerned in the SAR temporal composite (fig. 9).

\section{Elephant-Ear Increase Related to HV and LFC}

One possible consequence of decreasing $P$. australis marsh density was the replacement by elephant-ear at field and observed regional sites. The initial contention was that elephant-ear replacement would result in increased LFC and decreased HV density in comparison to pure $P$. australis marsh. Although scatter reduced confidence, the correlation results support the HV-density decrease but not the LFC increase. The elephant-ear addition increasingly dampened the 2018 to 2019 HV-density and LFC increase until elephant-ear covered 60-80 percent of the site. At that point, the overall 2018 to 2019 HV-density and LFC increase was reversed. Work is needed to assess whether these patterns of elephant-ear increase and HV-density and LFC decrease can be used to spatially map probable locations of elephant-ear increase throughout the Delta NWR for 2019.

\section{Technology Transfer}

To maximize the potential for technology transfer, the SAR mapping is based on consistently collected ALOS satellite image data that, along with free optical data, can be processed with free software implemented on a local workstation and subsequently analyzed and output with free geographic information system software.

\section{Summary}

The U.S. Geological Survey (USGS), in cooperation with the U.S. Fish and Wildlife Service (FWS), used satellite mapping of Phragmites australis marsh density along with Advanced Land Observing Satellite (ALOS) L-band synthetic aperture radar (SAR) HV data to determine P. australis marsh dieback onset and progression in the lower Mississippi River Delta. The ALOS L-band SAR HV polarization provides a unique perspective of the lower Mississippi River Delta, and in particular, the FWS Delta National Wildlife Refuge (NWR) $P$. australis marsh density patterns. HV-density maps identified two broad classes of density: high density on berms lining the many canals and low P. australis marsh density in basins lying between intermediate berms. Density maps prepared for 2016, 2017, 2018, and 2019 indicated dramatic to subtle local changes of $P$. australis density throughout the lower Mississippi River Delta within a backdrop of broad yearly change. The yearly density changes mostly aligned with existing optical live fractional cover (LFC) status and trends maps, but local variability within density and LFC maps differed. That yearly alignment and local difference motivated the development of a unique tool to detect and track P. australis marsh change and to assess the causal nature of the change. This tool comprised trajectory plots complemented by tabular statistics to represent the coupled temporal changes of both critical biophysical components of the $P$. australis marsh: LFC and density.

Trajectory plots and tabular statistics were developed for berm and basin $P$. australis marsh sites by using data extracted from the yearly 2016 to 2019 HV-density and LFC maps of sites throughout the Delta NWR. Trajectories indicated a dramatic density decrease from 2016 to 2017 at all 8 berm sites and 6 of the 12 basin sites; LFC change was mixed. Full HV and LFC recovery occurred at most of those sites by 2019 . Between November 2018 and August 2019, however, partial replacement of $P$. australis marsh by elephant-ear occurred at most of the berm field sites, and replacement increased in two observed basin sites. In addition, the trajectory tool identified abnormal trajectories for two basin sites that had transitioned to a mixture of plant species and for a third basin site that had 
transitioned to degraded marsh. A fourth basin site was identified as having European $P$. australis instead of the dominant $P$. australis. The trajectory tool exposed a density loss event that may have increased the $P$. australis marsh exposure to latent replacement during the 2018 to 2019 elephant-ear growth spurt. These examples from the myriad patterns possible demonstrate the enhanced information the trajectory tool can provide for resource managers. This tool can help move management response from restoration to early detection and mitigation, thus decreasing irreversible changes, such as damage caused by insect infestation.

The same field data used in development of the trajectory tool were used to explore detection of elephant-ear replacement of $P$. australis marsh. The data indicated a significant negative relationship between HV-density change and change in the percentage of elephant-ear coverage from 2018 to 2019. A similar but more scattered decrease in LFC with increasing elephant-ear was indicated. Although corroboration is needed, evidence indicates that a refined trajectory tool could be used to detect $P$. australis marsh replacement.

\section{References Cited}

Baurick, T., 2017, Roseau cane plague on Louisiana coast might have started a year earlier: New Orleans, Louisiana, The Times-Picayune, August 12, 2017, accessed October 19, 2020, at https://www.nola.com/environment/ index.ssf/2017/08/mississippi_delta_wetland_plag.html.

Bourgeau-Chavez, L.L., Kowalski, K.P., Carlson Mazur, M.L., Scarbrough, K.A., Powell, R.B., Brooks, C.N., Huberty, B., Jenkins, L.K., Banda, E.C., Galbraith, D.M., Laubach, Z.M., and Riordan, K., 2013, Mapping invasive Phragmities australis in the coastal Great Lakes with ALOS PALSAR satellite imagery for decision support: Journal of Great Lakes Research, v. 39, no. 1, p. 65-77, accessed February 23, 2021, at https://doi.org/10.1016/j.jglr.2012.11.001.

Bourgeau-Chavez, L.L., Riordan, K., Powell, R.B., Miller, N., and Nowels, M., 2009, Improving wetland characterization with multi-sensor, multi-temporal SAR and optical/infrared data fusion, in Jedlovec, G., ed., Advances in geoscience and remote sensing, p. 679-708, accessed February 23, 2021, at https://cdn.intechopen.com/pdfs/9542.pdf.

Coastal Protection and Restoration Authority, 2020, Coastwide Reference Monitoring System: Coastal Protection and Restoration Authority online database, accessed November 25, 2020, at https://www.lacoast.gov/CRMS/.

Dugas, J.L., SooHoo, W.M., Enwright, N.M., and Couvillion, B.R., 2018, Phragmites australis maps and change, Delta National Wildlife Refuge, Louisiana (2011, 2013, 2016): U.S. Geological Survey data release, accessed March 8, 2021, at https://doi.org/10.5066/F7K936RG.
Knight, I., Cronin, J., Diaz, R., Nyman, A., and Wilson, B., 2019, Understanding the role the roseau cane scale on Phragmites die-offs at the Mississippi River Delta: Louisiana State University AgCenter, 30-slide presentation, May 10, 2019.

Ramsey, E., III, 1998, Radar remote sensing of wetlands, in Lunetta, R., and Elvidge, C., eds., Remote sensing change detection-Environmental monitoring methods and applications: Ann Arbor, Michigan, Ann Arbor Press, Inc., p. 211-243.

Ramsey, E., III, and Jensen, J., 1995, Modeling mangrove canopy reflectance using a light interaction model and an optimization technique, in Lyon, J., and McCarthy, J., eds., Wetland and environmental applications of GIS: Boca Raton, Florida, CRC Press, Inc., p. 61-81.

Ramsey, E., III, Nelson, G., Sapkota, S., Laine, S., Verdi, J., and Krasznay, S., 1999, Using multiple polarization L band radar to monitor marsh burn recovery: IEEE Transactions on Geoscience and Remote Sensing, v. 37, no. 1, p. 635-639. [Also available at https://doi.org/10.1109/ 36.739136.]

Ramsey, E., III, and Rangoonwala, A., 2017, Mapping the change of Phragmites australis live biomass in the lower Mississippi River Delta marshes: U.S. Geological Survey Open-File Report 2017-1098, accessed February 23, 2021, at https://doi.org/10.3133/ofr20171098.

Ramsey, E., III, Rangoonwala, A., and Bannister, T., 2013, Coastal flood inundation monitoring with satellite C-band and L-band synthetic aperture radar data: Journal of the American Water Resources Association, v. 49, no. 6, p. 1239-1260, accessed February 23, 2021, at https://doi.org/10.1111/jawr.12082.

Ramsey, E., III, Rangoonwala, A., Chi, Z., Jones, C.E., and Bannister, T., 2014, Marsh dieback, loss, and recovery mapped with satellite optical, airborne polarimetric radar, and field data: Remote Sensing of Environment, v. 152, p. 364-374. [Also available at https://doi.org/10.1016/ j.rse.2014.07.002.]

Ramsey, E., III, Rangoonwala, A., and Jones, C.E., 2015, Structural classification of marshes with polarimetric SAR highlighting the temporal mapping of marshes exposed to oil: Remote Sensing, v. 7, no. 9, p. 11295-11321, accessed February 23, 2021, at https://doi.org/10.3390/rs70911295.

Ramsey, E., III, Rangoonwala, A., and Jones, C.E., 2016, Marsh canopy structure changes and the Deepwater Horizon oil spill: Remote Sensing of Environment, v. 186, p. 350-357. [Also available at https://doi.org/10.1016/ j.rse.2016.08.001.] 
Rangoonwala, A., Howard, R.J., and Ramsey, E.W., III, 2020, Mapping Phragmites australis live fractional cover in the lower Mississippi River Delta, Louisiana: U.S. Geological Survey Open-File Report 2020-1131, 24 p., accessed

February 23, 2021, at https://doi.org/10.3133/ofr20201131.
Rundquist, D., Gitelson, A., Leavitt, B., Zygielbaum, A., Perk, R., and Keydan, G., 2014, Elements of an integrated phenotyping system for monitoring crop status at canopy level: Agronomy (Basel), v. 4, no. 1, p. 108-123, accessed October 12, 2020, at https://doi.org/10.3390/ agronomy4010108.
For more information about this publication, contact Director, Wetland and Aquatic Research Center U.S. Geological Survey

700 Cajundome Blvd.

Lafayette, Louisiana 70506

For additional information, visit

https://www.usgs.gov/centers/wetland-and-aquatic-research-centerwarc

Publishing support provided by

Lafayette Publishing Service Center 




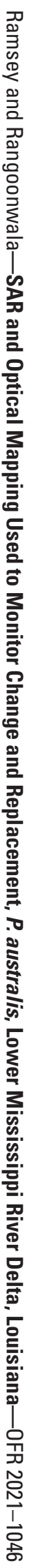

